\title{
COLLABORATION AND SUSTAINABLE AGRI-FOOD SUPLY CHAIN: A LITERATURE REVIEW
}

\author{
Wike Agustin Prima Dania ${ }^{12}$, Ke Xing $^{1}$, Yousef Amer ${ }^{1}$ \\ ${ }^{1}$ University of South Australia, 101 Curie St, Adelaide 5001, South Australia \\ ${ }^{2}$ University of Brawijaya, 1 Veteran St, Malang 65144, Indonesia \\ E-Mail: wike.dania@mymail.unisa.edu.au
}

\begin{abstract}
Maintaining collaboration among the entire stages in the agri-food supply chain to achieve sustainability is complex. All the stakeholders involved in the activities have to prioritize their financial benefits without putting aside social development and environmental responsibilities. Some scholars have paid attention to this topic. The objective of this paper is to review current research on sustainable supply chain and collaboration model in agri-food industry. Sustainability aspects that consist of economic, environment, and social and the model of sustainable supply chain in agrifood industry are analyzed. Moreover, collaboration in sustainable agri-food supply chain management is also studied thoroughly from vertical and horizontal perspectives. The result shows that there are few studies focusing on the integrated collaboration to achieve sustainable supply chain system. Additionally, not all sustainable aspects are covered thoroughly. The scholars pays more attention to economic and environmental aspects than social aspects. Furthermore, some studies only focus on one type of collaboration in sustainable agri-food supply chain. Often, these studies do not even consider all elements in the triple bottom line.
\end{abstract}

Keywords: sustainable supply chain, agri-food industry, collaboration

\section{INTRODUCTION}

Sustainable supply chain and collaboration is the key concept that essential to be applied in business environment, especially agri-food industry. Those concepts have been discussed in the literature. The purpose of this paper to review the current research in both area and to identify the limitations and provide suggestions for the future research in agri-food industry related to sustainable supply chain collaboration. In specifically, this study covers sustainability aspects in sustainable supply chain management in agri-food industry that consists of economics, environment, and social dimensions. The sustainable supply chain management models in agri-food industry also discussed comprehensively. Moreover, collaboration models in sustainable agri-food supply chain management are investigated by clustered it into vertical collaboration, horizontal collaboration, and the combination of both types of collaboration. Therefore, this review will highlight the area of improvement which lead to suggestion of the future works.

\section{Agri-food supply chain and sustainability}

Agri-food industry is one of the most important sectors in the world. It gives impacts in economic, environment, and social aspects in several countries. For example, agri-food sector supports the economic activities in national and international scopes in the US while maintain the human life (Maloni \& Brown, 2006). In Europe, this sector has significant impact on the economic, environmental, and social simultaneously (Turi, et.al., 2014). In Scotland, food and drink supply chain become major sector that support economic benefits in Scottish community and deal with large number of employee (Leat, et al., 2011). Moreover, agri-food industry has also supported economic benefits in developing countries. For examples, rapid changing on product and process innovation in agri-food supply chain brings significant impact on socioeconomic development in Malaysia (Mohezar \& Nor, 2014). In Indonesia, agri-food product such as sugar, rice, meat, soybean, corn, chili, red onion, and palm become the main commodities that support national long term development (Rusono et al, 2014).

Supporting the development of agri-food product, supply chain has the important role. In agri-food, supply chain encompasses all processes and activities from farmers and suppliers who provide raw material, food manufacturers who process the food products to increase the added value, distributors and retailers who distribute the product into the customers through the systematic business processes. Each stakeholder in agri-food supply chain suffers the cost and collects the benefit even though sometimes it is unfair for some stakeholders. Therefore, supply chain need to be maintained to spread the benefit along and across the supply chain in fair and positive ways.

The more complex a supply chain configuration is, the more challenges the parties will face. Global competitions and unique characteristics of agri-food products demand that the food chain maintains the food quality throughout the processes from farm to the end consumers. Otherwise, it will become waste since it cannot be consumed (Yu \& Nagurney, 2013). One of critical factors in the food supply chain is how to ensure fair collaboration among stakeholders and give attention to economic, environmental, social, organizational, marketing, food safety factors, and obligation over the firms, consumers, and society (Fritz \& Schiefer, 2008).

Deal with the complexity of agri-food supply chain, sustainability is one of perspectives that can be applied to maintain the competitive strategies in economic, environmental, and social aspects that is called triple bottom line (TBL). The economic dimension includes revenue, cost, and consumer satisfaction, and service level (Varsei, et al., 2014; Wang, et al., 2011). The environmental dimension refers to natural resource 
consumption, carbon footprint, environmental legislation, waste management, and hazardous chemical and materials (Sanders, 2012; Varsei, et al., 2014). The social dimension covers impacts on a society such as working conditions, community development, consumer health and safety, human rights and child labour (Gosling, et al., 2014; Klassen \& Vereecke, 2012; Mota, et al., 2014). Within those three dimensions, optimal competitive advantages can be achieved while support the social development and reduce the environmental impacts.

There are several issues raised in the agri-food industry regarding the sustainability. The requirements of product quality assurance without compromising the price, the availability of natural resources and the continuity of raw material without damaging the environment, climate change, and employee welfare have become the main targets of consumers and societies. The dependence on weather, short shelf life, limited raw materials, food safety regulations, and global competition force the stakeholders to keep abreast of the demographic changes in order to offer high quality, value added, and sophisticated food products in the right time and the right quantity to consumers. On the other hand, financial benefits will remain the main priority to be achieved whilst supporting social development and environmental responsibilities. Another critical issue is material handling processes which require particular treatments and conditions due to the unique food product characteristics (fragile, perishable, and lower yield). Those issues can be addressed if there is strong commitment from all stakeholders involved to achieve the competitive advantages without sacrifice certain parts in supply chain.

\section{Collaboration in sustainable agri-food supply chain}

Strong commitment among the stakeholders involved can be realized in the form of collaboration. Supply chain collaboration is a joint partnership within the various stages in supply chain as well as its external environments to optimize their competitive advantage throughout the entire processes (Cao \& Zhang, 2011; Liao \& Kuo, 2014). Collaboration is important to support the long term partnership and spread the benefits throughout the entire supply chain system, from strategic level into operational level. Within collaboration, stakeholders able to share their assets (materials, labor, infrastructures, facilities and equipment, and machines) and their capabilities (technology, business processes, policy and legislation, and finance). Therefore, they can reduce the uncertainty, share the risk and cost, and able to serve customers in the right time, right quantity, and right quality without disregards the interest of other stakeholders.

There are two types of collaboration that should be viewed as a single entity, namely vertical collaboration and horizontal collaboration (Figure 1). Vertical collaboration is relationship among stakeholders from upstream to downstream along the supply chain. Horizontal collaboration is relationship among stakeholders that play in the same level including competitors and complementary, as well as external parties such as government, NGOs, associations, and universities. Those two types of collaboration have to be considered in order to achieve a better sustainability system for all stakeholders without adversely suffering other stakeholders such as local farmer and SMEs. Without collaboration, the price that comes to consumers will be higher because each stakeholder will increase the price to get the higher benefit and to minimize the risk. Therefore, collaboration is important to increase the product's value and to ensure the flexibility of the food production while following the environmental policy integration (Ernšteins, et al., 2013).

In the last decade, stakeholders in food industry have been started to concern about collaboration in achieving the SSC system targets since it gains optimal benefits in maximising the profit and minimising the risk among the parties involved. However, maintaining supply chain collaboration among the entire stages in the sugar supply chain is complex. The more stakeholders take part in the collaboration system, the more complex the system becomes. The lack of support from stakeholders, insufficient assessment systems, limited information systems, organizational culture, and reluctance to change create obstacles for the application of the collaborative systems in sugar supply chain (Bezuidenhout, et al., 2012). On the other hand, sufficient technology and information are required to support the collaboration. In addition, to build mutual trust among partners, there needs to be eagerness from both parties to commit to a positive collaboration.

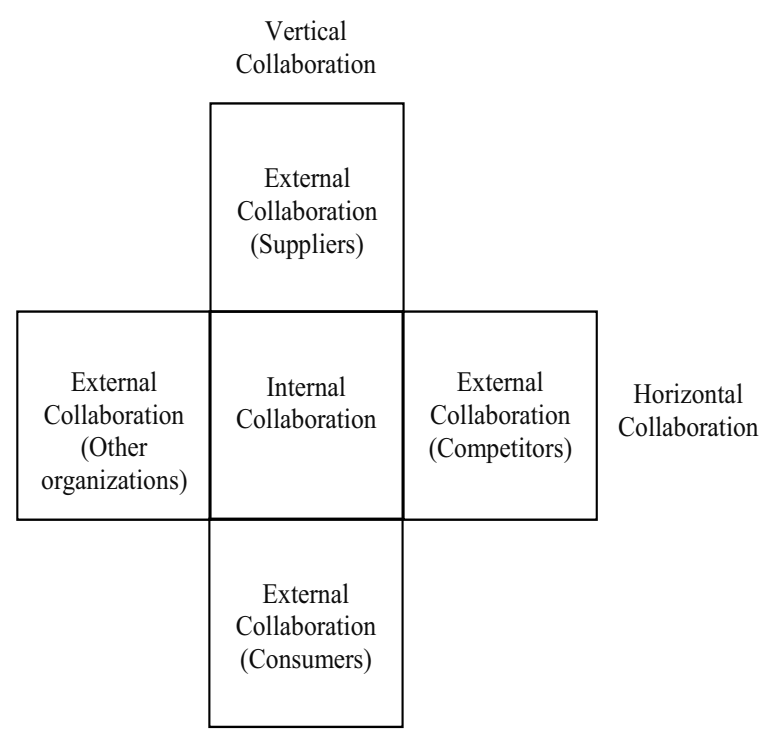

Figure-1. The Scope of Collaboration (Barratt 2004)

\section{LITERATURE REVIEW}

This section will be started by reviewing the dimensions of sustainable supply chain management in agri-food industry that consist of economic, environment, and social dimensions. Furthermore, how these dimensions have been used in the current sustainable supply chain model, specifically for agri-food industry, are also analysed. The last, research related to collaboration among stakeholders in agri-food supply chain management is identified. Therefore, it will give overview about the current research in both concepts that can lead to the identifying area for further research. 


\section{Sustainable supply chain management in agri-food industry}

In agri-food industry, sustainability is a concept that is still continuously improved. Food industry has a main role in sustaining consumers' health, taking part in an economic growth, and assuring an environmental impact reduction (Turi, et al., 2014). Therefore, sustainability is important for maintaining a value, awareness, society, and business reputation as well as enhancing a business environment and cooperation along a supply chain (Lin \& Tseng, 2014; Shokri, et al., 2014). Consisting of economic, environment, and social aspects, it is expected to respond to the dynamic environment in the food supply chain that has high food safety expectation, food regulation, and environmental legislation (Validi, et al., 2014). Moreover, the implementation of sustainability in an agri-food supply chain can be seen as an effective way to attract stakeholders to collaborate in achieving common goals (Rota, et al., 2013).

\section{Economic Dimensions in Agri-food Industry}

Economic dimensions are critical drivers in food business processes which implement sustainability (Shokri, et al., 2014). These dimensions refer to an allocation of resources in an appropriate manner to achieve efficiency and competitiveness to enhance contribution to the society (Leat, et al., 2011). The implementation of sustainability may lead to an incremental cost while adjusting internal and external facilities to create the advantages for all food business partners ( $\mathrm{Li}$, et al., 2014). Indeed, economic dimensions are influenced by social and environmental dimensions while they become the most important aspect in the sustainable supply chain (Yakovleva, et al., 2010).

Economic dimensions can be categorized into macroeconomics and microeconomic factors (Brandenburg, et al. 2014). Macroeconomic factors focus on labour productivity, market concentration, and import dependency under economic sustainability to achieve several goals such as promoting the economic growth, enhancing the competitive economy, and altering the customers preferences in food products (Yakovleva, et al., 2012). Microeconomic factors address revenues, production and transportation costs, and overtime costs as economic indicators (Dwi, et al. 2013). In addition, Yan and Ma (2012) assessed the economic dimensions by using inventory level and supply cost (procurement aspect), energy and fuel costs, delivery methods, inefficiency operation processes (internal operation), packaging materials and suitability between packaging and product requirements (product development and stewardship). Based on the survey, they proposed that sustainability in the food industry can be achieved by creating the proper business model, finding the trade-off between quality and cost-effectiveness, and finding the mature sourcing (Gold, et al., 2013).

\section{Environmental Dimensions in Agri-food Industry}

While running the business, the decision making is not only consider the economic aspects, they also have to pay attention to environmental aspects (Ala-Harja \& Helo, 2014). Currently, most countries need to support the reduction of GHG emissions since the declaration of
Kyoto Protocol which has a target to achieve it in the next certain years (Ramanathan, et al., 2014). In the low income countries, the contribution of the carbon footprint in food industry is higher compare to developed countries (Li, et al, 2014).

Environmental dimensions encompass input oriented (energy and natural resources) and output oriented indicators (waste and pollution) (Brandenburg, et al., 2014). Yan and Ma (2012) divided the environment supply chain issues into three categories, namely procurement (raw material, long and short term supply, waste and packaging), internal operation (water, air, soil pollution, health impact, and waste management), and product development and stewardship (product impact, substitute product, disposal, and traceability). On the other hand, Leat, et al., (2011) argued that there are three major categories in the environmental issue, namely climate change and eco-efficiency, green production and food safety, and animal welfare.

\section{Social Dimensions in Agri-food Industry}

Social issues is also needed to be considered in all strategic management processes in supply chain, even though these aspects are the most difficult aspect to be measured compare to others since it is has correlation with intangible aspects such as with culture, social communities, lifestyle, politics, health, human rights, and communities' aspiration (Vachon \& Mao, 2008; Wang, et al. 2011) (Cambero \& Sowlati, 2014). However, social standards such as ISO 26000 and Social Accountability SA8000 are still beyond the notice of organization management systems in the agri-food supply chain (Gold, et al., 2013).

The social focus in the food industries can be related to the raw material procurement from the local farmer, vitamin added in the local food, and increase the local income by providing the healthy and affordable local products (Gold, et al., 2013). These social dimensions support community development, labour opportunities, and human welfare (Leat, et al., 2011). Yakovleva, et al., (2012) determined wages, employment, and gender ratio to survive in creating fair market share and maintain productivity. Yan and Ma (2012) added labour standards, life balances, working hours, consumer demands, and inflation become the indicator in social dimensions. Furthermore, quantitative indicators have been established to measure the social dimensions such as number of employees trained, management levels with specific environment responsibility, number of improvement suggestions submitted by employees (Turi, et al., 2014).

\section{Models of sustainable supply chain management in agri-food industry}

Sustainable supply chain management is important to be applied in agri-food industry. It will influence not only internal organizations but also external relationship with other parties. It will help the development of socio-economic and environmental aspects, as well science and technology (Li, et al., 2014). These sustainability aspects also give a strong influence in the food supply chain particularly with regard to the natural resources and labour issues, health and safety, biotechnology, fair trade, community, and procurement 
(Maloni \& Brown, 2006). Research in sustainable agrifood supply chain is limited. Some models for assessing sustainable agri-food supply chain from various perspectives. However, not all of the models cover economic, environment, and social dimensions. In this section, the current research on sustainable supply chain management in agri-food industry has been investigated to identify the sustainability dimensions and indicators used that are shown in Table 1.

Table-1. Research in Sustainable Agri-food Supply Chain

\begin{tabular}{|c|c|c|c|}
\hline Authors & Industries & $\begin{array}{l}\text { Sustainability } \\
\text { Dimensions }\end{array}$ & Indicators \\
\hline \multirow{3}{*}{$\begin{array}{l}\text { Hamprecht et al. } \\
(2005)\end{array}$} & \multirow{3}{*}{$\begin{array}{l}\text { Nestle food supply } \\
\text { chain }\end{array}$} & Economics & - \\
\hline & & Environmental & Nutrition demands of the soils \\
\hline & & Social & Labour standard \\
\hline \multirow{3}{*}{ Egilmez et al. (2014) } & \multirow{3}{*}{$\begin{array}{l}33 \text { U.S. food } \\
\text { manufacturing } \\
\text { sectors }\end{array}$} & Economics & - \\
\hline & & Environmental & $\begin{array}{l}\text { The carbon footprint, the water withdrawals } \\
\text { impact category, the energy footprint of each } \\
\text { sector, the cropland footprint, the grazing land } \\
\text { footprint, the forestland footprint, and the fishery } \\
\text { land footprint }\end{array}$ \\
\hline & & Social & - \\
\hline \multirow{3}{*}{$\begin{array}{l}\text { Validi, Bhattacharya } \\
\text { and Byrne (2014) }\end{array}$} & \multirow{3}{*}{$\begin{array}{l}\text { Irish dairy market } \\
\text { supply chain }\end{array}$} & Economics & Total distribution cost \\
\hline & & Environmental & $\mathrm{CO}_{2}$ emission from transportation \\
\hline & & Social & - \\
\hline \multirow{3}{*}{$\begin{array}{l}\text { Zanoni and Zavanella } \\
(2012)\end{array}$} & \multirow{3}{*}{$\begin{array}{l}\text { Chilled or frozen } \\
\text { foods supply chain }\end{array}$} & Economics & Distribution cost \\
\hline & & Environmental & Energy effort required \\
\hline & & Social & - \\
\hline \multirow{3}{*}{ Bourlakis et al. (2014) } & \multirow{3}{*}{$\begin{array}{l}\text { Greek food supply } \\
\text { chain }\end{array}$} & Economics & $\begin{array}{l}\text { Materials cost, storage cost, delivery and } \\
\text { distribution cost, financial cost, gross profit } \\
\text { margin, flexibility, responsiveness, and quality }\end{array}$ \\
\hline & & Environmental & energy consumption, and waste \\
\hline & & Social & $\begin{array}{l}\text { Firm's perception of its own supply chain } \\
\text { performance, and firm's perceptions of market } \\
\text { opinion regarding its supply chain performance }\end{array}$ \\
\hline \multirow{3}{*}{ Yakovleva (2007) } & \multirow{3}{*}{ U.K. food industries } & Economics & $\begin{array}{l}\text { Productivity, diversity and structure of the } \\
\text { industry, and reducing transportation of imported } \\
\text { products }\end{array}$ \\
\hline & & Environmental & $\begin{array}{l}\text { Energy consumption, water consumption, and } \\
\text { waste disposal }\end{array}$ \\
\hline & & Social & $\begin{array}{l}\text { Employment volumes, quality of employment, } \\
\text { and gender balance at workplace }\end{array}$ \\
\hline \multirow[t]{3}{*}{$\begin{array}{l}\text { Tajbakhsh and Hassini } \\
(2014)\end{array}$} & \multirow[t]{3}{*}{ U.K. food industries } & Economics & $\begin{array}{l}\text { Raw material cost, transportation cost, supplier } \\
\text { capability factor, defect-free parts per million, } \\
\text { advertisement cost, investment in sustainability } \\
\text { design, personnel cost, service diversity, time } \\
\text { deliveries, and procurement cost }\end{array}$ \\
\hline & & Environmental & $\mathrm{CO}_{2}$ emission, and number of green products \\
\hline & & Social & $\begin{array}{l}\text { Average reputation factor, and average customer } \\
\text { satisfaction factor }\end{array}$ \\
\hline \multirow{3}{*}{$\begin{array}{l}\text { Turi, Goncalves and } \\
\text { Mocan (2014) }\end{array}$} & \multirow{3}{*}{ U.K. food industries } & Economics & $\begin{array}{l}\text { Transport cost, perfect order percentage, and } \\
\text { total validity period in transport }\end{array}$ \\
\hline & & Environmental & $\begin{array}{l}\text { Reverse logistics, reduce energy consumption, } \\
\text { and } \mathrm{CO}_{2}\end{array}$ \\
\hline & & Social & $\begin{array}{l}\text { Number of employees trained, management level } \\
\text { with specific environment responsibilities, and } \\
\text { number of improvement suggestion submitted by } \\
\text { employees }\end{array}$ \\
\hline
\end{tabular}

Some research only focuses on environmental and economic aspects in sustainable supply chain. They tried to link the environmental impact into economic value in their model. For instance, Hamprecht et al. (2005) developed a model to control the sustainability of upstream material flow in cereal and fresh milk industry. It adapted total quality management (TQM) to support the social development while following the environmental policy by monitoring the labour standards and the nutrition demands of the land. The result indicates the important variable to achieve the high quality fulfil the food safety regulation is traceability, Moreover, the incentives 
program for high quality farmers is also help to support the quality assurance. Other research also argue that sustainability has strong correlation with quality, temperature and energy (Zanoni \& Zavanella, 2012). This model has been proposed to enhance the preservation process in chilled or frozen foods by linking economic and environmental dimensions. Another model that was proposed by Turi, Goncalves and Mocan (2014) considers quality, time, cost, logistics, and productivity to assess the sustainability in food industry.

Sustainability performance can be assessed by several ways. Economic Input-Output Life Cycle Assessment (EIO-LCA) and Data Envelopment Analysis that has been designed by Egilmez et al. (2014) can be applied to analyse the direct and indirect carbon footprints. In this model, Sustainability Performance Index (SPI) has been used as an input for policy makers to propose recommendations. Other model has been designed by Validi, Bhattacharya and Byrne (2014) to analyse the sustainability performance of two layers supply chain from manufacturer to drop off points of one dairy product supply chain. This study only focus on environmental perspectives by emerging trade-off between carbon emissions and distribution costs.

Furthermore, there are some research that considered all triple bottom line aspects in their proposed model. Sustainability can be assessed based on quality, responsiveness, flexibility, consumption, and total supply chain (Bourlakis et al. 2014). Comparing between different food firm sizes (micro, small, and medium enterprises), it shows that medium manufacturers are more mature in maintaining the sustainable supply chain, because they tend to play in local scopes that have fewer risks and under control, and they seem to be more responsive and flexible. However, small firms, except manufacturers, present better sustainability performance.

Yakovleva (2007) proposed a model that can be applied to benchmark different kind of agri-food companies in the UK based on economic, environment, and social dimensions. She recommended several indicator and analysed it by using spider diagram. In the current year, Yakovleva, Sarkis and Sloan (2012) applied another method for benchmarking. They use Analytic Hierarchy Process (AHP) and expert opinion to determine overall index of sustainability. However, this study has limitation since it is assumed that all variables are independent.
Therefore, they suggested Analytic Network Process (ANP) and optimisation tool to be applied in the future study. Moreover, efficiency score of sustainable supply chain can be analysed by using Data Envelopment Analysis (DEA) (Tajbakhsh \& Hassini, 2014). This model has the ability to analyse the individual and overall efficiency score of stakeholders in beverage industry from farmer to retailer.

In summary, this review highlights that not all of the studies cover all the three aspects of triple bottom line on models as well as all stages in the supply chain. Some studies also limit the case by assuming that all indicators are independent. In fact, there are many potential issues that still need to be investigated comprehensively.

\section{Collaboration in agri-food supply chain management}

Collaboration is needed in agri-food supply chain system in order to minimize cost, increase the profit, fulfil the quality assurance, and as the result is gaining the trust from consumers. Collaboration involves all activities such as production processes, sharing information and infrastructure, skills and knowledge among all stakeholders in the agri-food supply chain such as farmers, food manufacturers, distributors, retailers, consumers, government, NGOs, and finance providers. Each stakeholder has limitation that can be solved by conducting collaboration. This collaboration need strong commitment from all organization involved to achieve the common goal (Steele \& Feyerherm, 2013).

However, there is a complexity in the application of collaboration, particularly integrated collaborations in a agri-food industry. Trust, Commitment, and willingness to share risks become the main keys in achieving a long term goal to create strong collaboration (Bezuidenhout, et al., 2012). Unfortunately, encouraging stakeholders to address these characteristics is not an easy task, particularly for food industry that has a complex system (Rota, et al., 2013). Moreover, the existence of global regulations, global trading, and emerging consumer preferences also bring another risk to the collaboration system (Matopoulos, et al., 2007).

Various studies on collaboration on agri-food supply chain have been conducted. There are some studies that only focus on vertical collaboration, horizontal collaboration, or considering both types of collaboration that is shown in Table 2.

Table-2. Research on Collaboration in Agri-food Supply Chain Management

\begin{tabular}{|c|c|c|c|}
\hline Authors & Industries & Vertical Collaboration & Horizontal Collaboration \\
\hline Masuku et al. (2003) & $\begin{array}{l}\text { Swaziland sugar supply chain } \\
\text { (growers-millers) }\end{array}$ & $\sqrt{ }$ & \\
\hline Matopoulos et al. (2007) & $\begin{array}{l}\text { Greece food catering } \\
\text { (growers-processors) }\end{array}$ & $\sqrt{ }$ & \\
\hline Proches and Bodhanya (2013) & $\begin{array}{l}\text { South Africa sugar supply } \\
\text { chain } \\
\text { (upstream supply chain) }\end{array}$ & $\sqrt{ }$ & \\
\hline $\begin{array}{l}\text { Rota, Reynolds and Zanasi } \\
(2013)\end{array}$ & $\begin{array}{l}\text { Non-specific food industries } \\
\text { (food manufacturers-retailers) }\end{array}$ & $\sqrt{ }$ & \\
\hline Hildbrand and Bodhanya (2014) & $\begin{array}{l}\text { South Africa sugar supply } \\
\text { chain } \\
\text { (growers-millers) }\end{array}$ & $\sqrt{ }$ & \\
\hline Laham (2014) & $\begin{array}{l}\text { Malaysian pineapple supply } \\
\text { chain }\end{array}$ & $\sqrt{ }$ & \\
\hline
\end{tabular}




\begin{tabular}{|l|l|c|c|}
\hline $\begin{array}{l}\text { Van der Krogt, Nilsson and Høst } \\
(2007)\end{array}$ & European dairy industries & & $\sqrt{ }$ \\
\hline Malaza and Myeni (2009) & Swaziland Sugarcane farmers & & $\sqrt{ }$ \\
\hline Ghaderi et al. (2012) & confectionary SMEs & & $\sqrt{ }$ \\
\hline McAdam et al. (2014) & $\begin{array}{l}\text { artisan bakers' SMEs in the } \\
\text { UK }\end{array}$ & $\sqrt{ }$ \\
\hline Wright, Score \& Conner (2007) & $\begin{array}{l}\text { Michigan food system } \\
\text { economic partnership }\end{array}$ & $\sqrt{ }$ \\
\hline Weaver (2008) & Non-specific food industries & $\sqrt{ }$ \\
\hline Gellynck and Kühne (2010) & $\begin{array}{l}\text { traditional food supply chain } \\
\text { in Belgium, Hungary, and } \\
\text { Italy }\end{array}$ & $\begin{array}{l} \\
\text { Canadian seafood supply } \\
\text { chain }\end{array}$ & $\sqrt{ }$ \\
\hline Steele and Feyerherm (2013) & Tanzania banana supply chain & $\sqrt{ }$ \\
\hline Warsanga (2014) & Scotland pork supply system & $\sqrt{ }$ \\
\hline Leat and Revoredo-Giha (2013) & & & $\sqrt{ }$ \\
\hline
\end{tabular}

\section{Vertical Collaboration}

Various studies on vertical collaboration on agrifood supply chain have been conducted. In dyadic relationship between growers and millers in Swaziland sugar industry supply chain, organizational behaviour such as commitment, trust, and cooperation are important in supporting the contractual relationship (Masuku et al. 2003). Their research investigated that individual trust is more important than authorized relationship. On the other hand, in fresh product and food processing supply chain, it is important to combine macro factors (globalization, consolidation, consumers' attitude, and fixed regulations) and micro factors (industry's structure and product features) (Matopoulos, et al., 2007). These factors are linked with the two pillars of supply chain: design and the government of supply chain activities, and the establishment and the maintenance of supply chain relationship.

A theoretical framework, such as complexity theory can also be applied to analyse the collaboration among stakeholders in supply chain (Proches \& Bodhanya, 2013). In the upstream supply chain interaction, that involving sugarcane farmers, hauliers, and millers, it indicates that different goals, interests, power levels, and perspectives become the obstacles to generate good collaboration. Other theoretical frameworks such as supply chain management, transaction cost economics, and resource based view theories can be used to analyse a sustainable relationship and collaboration (Rota, et al., 2013). The results suggest the key driver of sustainability that influences the performance of sustainability is vertical collaboration.

Another model, Viable System Model (VSM) can also be applied to analyse the complexity of supply chain collaboration (Hildbrand \& Bodhanya, 2014). In the farmers-millers interaction, inefficiency is tend to be caused by soft issues and organizational behaviour rather than hard issue. Additionally, local autonomy is important in supporting farmer-local mills relationship. Furthermore, qualitative approach also can be applied to analyse supply chain vertical collaboration (Laham, 2014). He divided supply chain into two categories, upstream supply chain and downstream supply chain and analyses their different characteristics based on product characteristics, business relationships, business processes, positions in supply chain, and information sharing. The results indicate that the business relationship is the most important drivers in collaboration. Furthermore, a high level collaboration exists in upstream supply chain.

\section{Horizontal Collaboration}

Beside vertical collaboration, some studies analyse the relationship among stakeholders that play in the same level including external organizations that is called horizontal collaboration. These studies discuss the collaboration from different perspectives and variables.

In dairy industries, cooperative and noncooperative organizations have differences preferences in applying horizontal collaboration (Van der Krogt, et al., 2007). Cooperative organizations prefer to join in joint ventures, mergers, general collaboration and licensing agreements. On the other hand, equity share holdings and acquisitions are more suitable for non-cooperative organizations. Cooperative strategies are more appropriate for industries that have limited equity capital, need minimum risk, and during the growth stage.

If horizontal collaboration is applied in sugarcane farmers' collaboration, strategic alliance, farm management, and ratoon management fund are important to overcome the common problems, such as high production costs, poor ratoon management, low income, and high levels of debt (Malaza \& Myeni, 2009). It will enhance the productivity and competitiveness among local farmers. Horizontal collaboration can also be applied in reducing outbound transportation among confectionary SMEs participating in a logistic system consortium (Ghaderi, et al., 2012). For SMEs that have small orders can implement the horizontal collaboration by combining the load among the parties.

Horizontal collaboration is also can be applied to support the relationship among the food retailers (Nielsen, et al., 2014). It is identified that collaboration among retailers need enthusiasm, strong commitment, a high level of maturity, and willingness to override individual actions. Companies prefer to cooperate with an organization that has a similar size, structure, capabilities, and resources. However, it is difficult to get strong commitment in the collaboration and supporting the sustainability. 


\section{Combining Vertical and Horizontal Collaboration}

Despite the fact that collaborations have been studied independently, some researchers realized that both vertical and horizontal collaborations are also important to be investigated comprehensively. Wright, Score and Conner (2007) investigated the collaboration among local government, universities, agri-business, and local societies. It shows that motivation from stakeholder to engage in collaboration form is important. The reasons are there is dependency of the community into agricultural aspects to achieve the prosperity and to support the socio economic development. Collaboration strategy also has the implication into pull innovation in agri-food supply chain to increase the value creation (Weaver, 2008). Vertical collaboration helps to gain better coordination within the supply chain stages in term of product design and development. However, the processing time can be reduced significantly by horizontal collaboration since innovation processes work parallel.

Another study discovered that both types of collaborations, vertical and horizontal, exist in the traditional food supply chain in Belgium, Hungary, and Italy (Gellynck \& Kühne, 2010). The result indicates that vertical collaboration is well established. However, horizontal collaboration only exists if there are associations among organizations. The biggest barrier in creating collaboration form is lack of understanding, trust, knowledge, financial and physical resources.

The difficulties to enhance the fair collaboration form is also happened in banana supply chain in Tanzania (Warsanga, 2014). Farmers suffer the most cost and get the less benefit compare to others. It indicates that the collaboration is inefficient. To overcome this problem, horizontal collaboration among farmers is important by creating association organization. Furthermore, power sharing and agreement among stakeholders in the within vertical collaboration are essential to support good quality of collaboration.

Another study argues that external collaboration is more important than internal collaboration within organization for controlling performance achievement (Steele \& Feyerherm, 2013). In seafood industry, sustainable organization can be achieved by strong commitment and organization's clarity. Furthermore, sustainable collaboration is also influenced by having good management systems and performance tracking. Moreover. risk management is important to be considered in achieving the flexibility through vertical and horizontal collaboration (Leat \& Revoredo-Giha, 2013). It shows that the flexibility of the primary supplier has an impact on the supply chain resilience. Therefore, good collaboration on facilitate risk management among the stakeholders is important.

\section{DISCUSSIONS}

Based on literature review, it can be seen that even though the agri-food industry has a significant influence on social and economic developments globally, research on sustainable agri-food supply chain is limited. Some studies do not cover all sustainability aspects. Most of them focus on economic and environmental aspects and disregards social aspects that also important to build the strong social development in the communities. Even though, they paid attention in all sustainability aspects, economic indicators are also more dominant rather than others since this aspect are easier to be quantified. Moreover, some studies also limit the case by assuming that all indicators are independent. However, in the more reality, there is possibility that the indicators have the correlation to each other (Kahraman, et al., 2006). Therefore, it can be potential issues that can be explored broadly in the future by analysis the dependency among variable and sub-variable.

Furthermore, some studies only focus on one type of collaboration in sustainable agri-food supply chain. Often, these studies do not even consider all elements in the triple bottom line. They focus on what collaboration strategies that are applicable in different food sectors from different perspectives. However, even though the products are different, the nature of the research is quite similar. Most of the studies show that indicators of sustainability such as food safety, quality, nutrient, natural resources, labour issues, energy, and carbon footprint become the main issues that need to be addressed in several agri-food industries. Moreover, even though the problems are discovered from different perspectives, the collaboration structures among the agri-food industries are similar. Mainly, it consists of suppliers/farmers, food manufacturers, distributors, and retailers. In addition, related to collaboration behaviour communication becomes the main problem in collaboration, despite the fact that there are other slightly different aspects that need to be concerned. Communication will lead to positive relationship (Bezuidenhout, et al., 2012). In brief, in the future studies, integrated collaboration model that can accommodate all sustainable aspects is potential to be investigates comprehensively. Moreover, other organizational theories can be applied to analyse the complexity of the collaboration to propose the integrated collaboration model.

\section{CONCLUSIONS}

Sustainability and collaboration are concept that is important in supporting the complex system in agri-food supply chain management. Sustainability is one of perspectives that can be applied to maintain the competitive strategies in economic, environmental, and social aspects that is called triple bottom line (TBL). Several studies discuss all those element, however economic aspects are still become dominant variables that are considered in analyzing the sustainable supply chain. It is important to achieve a better sustainability system for all stakeholders without adversely suffering other stakeholders such as local farmer and SMEs by reducing the uncertainty and sharing the risk and costs among stakeholders involves.

Moreover, only few research that consider both vertical and horizontal collaboration as a network to achieve the positive competitive advantages. Collaboration as a network will support the long term partnership and spread the benefits throughout the entire supply chain system, from strategic level into operational level. Both concepts brings significant impact on agri-food industry in term of achieving socio-economic development as well as supporting the reduction of environmental impacts in the world. From this literature review, it can be concluded that 
it is important to develop model can accommodate both sustainability and integrated collaboration model is essential. For the further literature review, methods that have been used to develop sustainable supply chain and collaboration in supply chain management need to be analyzed comprehensively. Moreover, review about assessment method to examine the robustness of collaboration among stakeholders also need to be considered

\section{REFERENCES}

Ala-Harja, H \& Helo, P 2014, 'Green supply chain decisions-case-based performance analysis from the food industry', Transportation Research Part E: Logistics and Transportation Review, vol. 69:97-107.

Barratt, M 2004, 'Understanding the meaning of collaboration in the supply chain', Supply Chain Management: An International Journal, vol.9(1):30-42.

Bezuidenhout, CN, Bodhanya, S \& Brenchley, L 2012, 'An analysis of collaboration in a sugarcane production and processing supply chain', British Food Journal, vol. 114(6):880-895.

Bourlakis, M, Maglaras, G, Aktas, E, Gallear, D \& Fotopoulos, C 2014, 'Firm size and sustainable performance in food supply chains: Insights from Greek SMEs', International Journal of Production Economics, vol.152:112-130.

Brandenburg, M, Govindan, K, Sarkis, J \& Seuring, S 2014, 'Quantitative models for sustainable supply chain management: Developments and directions', European Journal of Operational Research, vol.233(2):299-312.

Cambero, C \& Sowlati, T 2014, 'Assessment and optimization of forest biomass supply chains from economic, social and environmental perspectives - A review of literature', Renewable and Sustainable Energy Reviews, vol.36:62-73.

Cao, M \& Zhang, Q 2011, 'Supply chain collaboration: impact on collaborative advantage and firm performance', Journal of Operations Management, vol.29(3):163-180.

Dwi, Y, Nouaouri, I, Allaoui, H \& Goncalves, G 2013, 'Sustainable supply chain and collaboration: What is the link and what are the benefits?', 2nd International Conference on Sustainable Intelligent Manufacturing, SIM 2013, 631-636.

Egilmez, G, Kucukvar, M, Tatari, O \& Bhutta, MKS 2014, 'Supply chain sustainability assessment of the US food manufacturing sectors: A life cycle-based frontier approach', Resources, Conservation and Recycling, vol. 82:8-20.

Ernšteins, R, Lontone, A, Zvirbule, L \& Kauliņš, J (eds) 2013, Sustainable food governance development perspective on the local municipality level, University of Latvia, Latvia.
Fritz, M \& Schiefer, G 2008, 'Food chain management for sustainable food system development: a European research agenda', Agribusiness, vol.24(4):440-452.

Gellynck, X \& Kühne, B 2010, 'Horizontal and vertical networks for innovation in the traditional food sector', International Journal on Food System Dynamics, vol.1(2):123-132.

Ghaderi, H, Darestani, SA, Leman, Z \& Ismail, MY 2012, 'Horizontal collaboration in logistics: a feasible task for group purchasing', International Journal of Procurement Management, vol.5(1):43-54.

Gold, S, Hahn, R \& Seuring, S 2013, 'Sustainable supply chain management in "Base of the pyramid" food projects - A path to triple bottom line approaches for multinationals?', International Business Review, vol.22(5):784-799.

Gosling, J, Jia, F, Gong, Y \& Brown, S 2014, 'The role of supply chain leadership in the learning of sustainable practice: Toward an integrated framework', Journal of Cleaner Production, Available online 16 October 2014.

Hamprecht, J, Corsten, D, Noll, M \& Meier, E 2005, 'Controlling the sustainability of food supply chains', Supply Chain Management: An International Journal, vol.10(1):7-10.

Hildbrand, S \& Bodhanya, S 2014, 'Application of the viable system model in a complex sugarcane supply chain', British Food Journal, vol.116(12):2048-2068.

Kahraman, C, Ertay, T \& Büyüközkan, G 2006, 'A fuzzy optimization model for QFD planning process using analytic network approach', European Journal of Operational Research, vol. 171(2):390-411.

Klassen, RD \& Vereecke, A 2012, 'Social issues in supply chains: Capabilities link responsibility, risk (opportunity), and performance', International Journal of Production Economics, vol.140(1):103-115.

Laham, J 2014, 'Supply chain collaboration in the Malaysian pineapple chains', $\mathrm{PhD}$ thesis, School of Agriculture and Food Sciences, The University of Queensland.

Leat, P, Revoredo-Giha, C \& Lamprinopoulou, C 2011, 'Scotland's food and drink policy discussion: Sustainability issues in the food supply chain', Sustainability, vol.3(4):605-631.

Leat, P \& Revoredo-Giha, C 2013, 'Risk and resilience in agri-food supply chains: the case of the ASDA PorkLink supply chain in Scotland', Supply Chain Management, vol. 18(2):219-231.

Li, D, Wang, X, Chan, HK \& Manzini, R 2014, 'Sustainable food supply chain management', International Journal of Production Economics, vol.152:1-8. 
Liao, S-H \& Kuo, F-I 2014, 'The study of relationships between the collaboration for supply chain, supply chain capabilities and firm performance: A case of the Taiwan's TFT-LCD industry', International Journal of Production Economics, vol.156:295-304.

Lin, Y-H \& Tseng, M-L 2014, 'Assessing the competitive priorities within sustainable supply chain management under uncertainty', Journal of Cleaner Production, Available online 17 July 2014.

Malaza, S \& Myeni, D 2009, 'Integrating smallholder growers into competitive sugarcane production', South African Sugarcane Technologists Association, vol.82:405408.

Maloni, MJ \& Brown, ME 2006, 'Corporate social responsibility in the supply chain: an application in the food industry', Journal of business ethics, vol.68(1):35-52.

Masuku, MB, Kirsten, JF, Van Rooyen, CJ \& Perret, S 2003, 'Contractual relationships between small-holder sugarcane growers and millers in the sugar industry supply chain in Swaziland', Agrekon: Agricultural Economics Research, Policy and Practice in Southern Africa, vol.42(3):183-199.

Matopoulos, A, Doukidis, GI, Vlachopoulou, M, Manthou, V \& Manos, B 2007, 'A conceptual framework for supply chain collaboration: Empirical evidence from the agri-food industry', Supply Chain Management: An International Journal, vol.12(3):177-186.

McAdam, M, McAdam, R, Dunn, A \& McCall, C 2014, 'Development of small and medium-sized enterprise horizontal innovation networks: UK agri-food sector study', International Small Business Journal, vol.32(7):830-853.

Mohezar, S \& Nor, MNM 2014, 'Could supply chain technology improve food operators' innovativeness? A developing country's perspective', Trends in Food Science \& Technology, vol.38(1):75-82.

Mota, B, Gomes, MI, Carvalho, A \& Barbosa-Povoa, AP 2014, 'Towards supply chain sustainability: economic, environmental and social design and planning', Journal of Cleaner Production, Available online 1 August 2014.

Nielsen, FAG, Angeli, F, Luppe, MR \& Giesbrecht da Silveira, JA 2014, 'Horizontal alliances among independents and non-integrated food retailers: A worldwide analysis ', International Journal of Business \& Commerce, vol.3(10):21-50.

Proches, CNG \& Bodhanya, S 2013, 'An analysis of multistakeholder interactions in the sugar industry using a social complexity framework', Problems and Perspectives in Management, vol.11(4):77-85.

Ramanathan, U, Bentley, Y \& Pang, G 2014, 'The role of collaboration in the UK green supply chains: An exploratory study of the perspectives of suppliers, logistics and retailers', Journal of Cleaner Production, vol.70:231241.

Rota, C, Reynolds, N \& Zanasi, C 2013, 'Sustainable food supply chains: The role of collaboration and sustainable relationships', International Journal of Business and Social Science, vol.4(4):45-53.

Rusono, N, Suanri, A, Candradijaya, A, Muharam, A, Tejaningsih, IM, Hadi, PU, Susilowati, SH \& Maulana, M 2014, Studi pendahuluan: Rencana Pembangunan Jangka Menengah Nasional (RPJMN) bidang pangan dan pertanian 2015-2019, Direktorat Pangan dan Pertanian,Bappenas, Jakarta, Indonesia.

Sanders, NR 2012, Supply chain management : A global perspective, John Wiley \&amp; Sons, Hoboken, NJ.

Shokri, A, Oglethorpe, D \& Nabhani, F 2014, 'Evaluating sustainability in the UK fast food supply chain', Journal of Manufacturing Technology Management, vol.25(8):12241244.

Steele, B \& Feyerherm, A 2013, 'Loblaw sustainable seafood: Transforming the seafood supply shain through network development and collaboration', Organizing for Sustainable Effectiveness, vol.3:101-132.

Tajbakhsh, A \& Hassini, E 2014, 'A data envelopment analysis approach to evaluate sustainability in supply chain networks', Journal of Cleaner Production, Available online 9 Agustus 2014.

Turi, A, Goncalves, G \& Mocan, M 2014, 'Challenges and competitiveness indicators for the sustainable development of the supply chain in food industry', Procedia - Social and Behavioral Sciences, vol.124:133-141.

Vachon, S \& Mao, Z 2008, 'Linking supply chain strength to sustainable development: A country-level analysis', Journal of Cleaner Production, vol.16(15):1552-1560.

Validi, S, Bhattacharya, A \& Byrne, PJ 2014, 'A case analysis of a sustainable food supply chain distribution system-A multi-objective approach', International Journal of Production Economics, vol.152:71-87.

Van der Krogt, D, Nilsson, J \& Høst, V 2007, 'The impact of cooperatives' risk aversion and equity capital constraints on their inter-firm consolidation and collaboration strategies - with an empirical study of the European dairy industry', Agribusiness, vol.23(4):453-472.

Varsei, M, Soosay, CA, Fahimnia, B \& Sarkis, J 2014, 'Framing sustainability performance of supply chains with multidimensional indicators', Supply Chain Management: An International Journal, vol.19(3):242-257.

Wang, PC, Halim, I, Adhitya, A \& Srinivasan, R 2011, 'Integrating economic, environmental and social indicators for sustainable supply chains', in E.N. Pistikopoulos, MCG \& Kokossis, AC (eds), Computer Aided Chemical Engineering, Elsevier, 1220-1224. 
Warsanga, WB 2014, 'Coordination and structure of agrifood value chains: Analysis of banana value chain strands in Tanzania', Journal of Economics and Sustainable Development, vol.5(7):71-78.

Weaver, RD 2008, 'Collaborative pull innovation: Origins and adoption in the new economy', Agribusiness, vol.24(3):388-402.

Wright, W, Score, M \& Conner, DS 2007, 'Food system makers: Motivational frames for catalyzing agri-food development through multi-stakeholder collaboration', Community Development, vol.38(3):39-59.

Yakovleva, N 2007, 'Measuring the sustainability of the food supply chain: A case study of the UK', Journal of Environmental Policy \& Planning, vol.9(1):75-100.

Yakovleva, N, Sarkis, J \& Sloan, T 2010, 'Sustainability indicators for the food supply chain', Woodhead Publishing Limited, 297-329.

Yakovleva, N, Sarkis, J \& Sloan, T 2012, 'Sustainable benchmarking of supply chains: The case of the food industry', International Journal of Production Research, vol.50(5):1297-1317.

Yan, X-h \& Ma, J 2012, 'Development of sustainable food supply chain', International Journal of Engineering \& Technology, vol.4(2):166-169.

Yu, M \& Nagurney, A 2013, 'Competitive food supply chain networks with application to fresh produce', European Journal of Operational Research, vol.224(2):273-282.

Zanoni, S \& Zavanella, L 2012, 'Chilled or frozen? Decision strategies for sustainable food supply chains', International Journal of Production Economics, vol. 140(2):731-736. 